\title{
Permeabilidade da membrana plasmática celular da beterraba: uma proposta de aula prática no ensino médio
}

\author{
Permeability of the beet cell plasma membrane: a proposal for a practical class in high school \\ Permeabilidad de la membrana plasmática celular de la remolacha: una propuesta para una clase
}

práctica en la escuela secundaria

Recebido: 02/03/2021 | Revisado: 07/03/2021 | Aceito: 08/03/2021 | Publicado: 16/03/2021

Tiago Maretti Gonçalves

ORCID: https://orcid.org/0000-0001-8971-0647 Universidade Federal de São Carlos, Brasil

E-mail: tiagobio1@ hotmail.com

\begin{abstract}
Resumo
A membrana plasmática é uma estrutura de grande importância presente em todos os seres vivos, desempenhando além do transporte de substâncias, diversas outras funções. O presente artigo possui como principal objetivo propor uma aula prática para facilitar o processo norteador do ensino e da aprendizagem da membrana celular aos alunos do ensino médio, na disciplina de Biologia. Utilizando materiais simples e de baixo custo como beterraba (Beta vulgaris, L.), água, querosene e álcool, essa aula permite ao professor trabalhar com os alunos os conceitos de permeabilidade da membrana, além de outros assuntos relacionados. Assim, a aula prática proposta pode ser reproduzida não somente no ambiente escolar, mas também em casa pelos discentes. Acreditamos que, a abordagem da aula prática proposta possa permitir a aplicação dos conceitos vivenciados nas aulas teóricas, facilitando a aprendizagem do tema proposto, além de promover a discussão e a proposição de hipóteses, despertando a ótica de experimentação científica dos discentes.
\end{abstract}

Palavras-chave: Aula prática; Membrana plasmática; Ensino; Metodologia alternativa.

\begin{abstract}
The plasma membrane is a structure of great importance present in all living beings, performing other functions in addition to the transport of substances. This article has as main objective to propose a practical class to facilitate the process of teaching and learning the cell membrane to high school students, in the discipline of Biology. Using simple and low-cost materials such as beets (Beta vulgaris, L.), water, kerosene and alcohol, this class allows the teacher to work with students on the concepts of membrane permeability, in addition to other related subjects. Thus, the proposed practical class can be reproduced not only in the school environment, but also at home by the students. We believe that the approach of the proposed practical class can allow the application of the concepts experienced in the theoretical classes, facilitating the learning of the proposed theme, in addition to promoting the discussion and proposition of hypotheses, awakening the perspective of scientific experimentation of the students.
\end{abstract}

Keywords: Practical class; Plasma membrane; Teaching; Alternative methodology.

\section{Resumen}

La membrana plasmática es una estructura de gran importancia presente en todos los seres vivos, que realiza otras funciones además del transporte de sustancias. Este artículo tiene como objetivo principal proponer una clase práctica para facilitar el proceso de enseñanza y aprendizaje de la membrana celular a estudiantes de secundaria, en la disciplina de Biología. Utilizando materiales simples y de bajo costo como remolacha (Beta vulgaris, L.), agua, queroseno y alcohol, esta clase permite al docente trabajar con los estudiantes los conceptos de permeabilidad de membranas, además de otras materias afines. Así, la clase práctica propuesta puede ser reproducida no solo en el entorno escolar, sino también en casa por los alumnos. Creemos que el abordaje de la clase práctica propuesta puede permitir la aplicación de los conceptos vividos en las clases teóricas, facilitando el aprendizaje del tema propuesto, además de promover la discusión y proposición de hipótesis, despertando la perspectiva de la experimentación científica de los estudiantes.

Palabras clave: Clase practica; Membrana plasmática; Enseñando; Metodología alternativa.

\section{Introdução}

A membrana plasmática celular é uma estrutura tridimensional fascinante e foi proposta por Singer e Nicolson em 1972, como um mosaico fluído (Singer \& Nicolson, 1972). Ela detém como principais funções o transporte de substâncias, a 
manutenção da integridade e o reconhecimento de célula a célula. No ensino médio, o seu estudo está inserido dentro da Biologia, mais especificamente na área da Citologia, que é caracterizada por conter muitos termos e estruturas morfológicas microscópicas. Assim, sua compreensão pode ser bastante dificultada pelos alunos, sendo um grande desafio para o docente ministrá-la em sala de aula. Dessa maneira, Rocha et al. (2007) ressaltam que, essa área da Biologia possui boa parte de seus conteúdos de maneira complexa para o entendimento do aluno, o que demanda ao professor a proposta de outras ferramentas de ensino.

Além disso, aulas pautadas no modo meramente expositivo podem desmotivar os alunos. Sobre isso, Goldschimidt et al. (2020) relatam que as aulas de maneira geral, são ministradas em um estilo monótono, na qual os docentes apenas se limitam na abordagem de conceitos, sem utilizarem ferramentas que facilitem o ensino, limitando-se assim a abordagem de conceitos, sem utilizarem materiais ou metodologias que facilitem a compreensão dos discentes, o que acarreta em uma aprendizagem mecânica, que rapidamente será esquecida. Para vencermos todos esses obstáculos, é de suma importância propor ao aluno novas metodologias de ensino com o objetivo de facilitar sua aprendizagem no tema proposto (Gonçalves, 2021) assim, uma das alternativas é a abordagem de aulas práticas no ensino de Citologia no ensino médio. Segundo Alffonso (2019), as aulas práticas possuem um grande impacto no processo de ensino dentro de Ciências e Biologia. Segundo o autor, nesse tipo de aula o discente consegue associar o conteúdo teórico com o fenômeno vivenciado, estimulando-o a criar hipóteses, podendo levá-lo a busca de novas informações. Neste sentido, Pimentel, Oliveira e Maciel (2017) afirmam que o uso de atividades experimentais é essencial para a articulação de fato entre teoria e a prática, na busca de um conhecimento transformador, tendo como base a experiência adquirida pelos alunos.

No entanto, o uso de aulas prática no ensino de Biologia ainda é pouco frequente no cotidiano escolar dos alunos. Tal problemática é discutida por Marandino, Selles e Ferreira (2009), sendo que os principais entraves para o baixo índice de realização de aulas práticas de Ciências e Biologia estão relacionadas à ordem estrutural, ao tempo curricular, à insegurança em ministrar essas aulas e à falta de controle sobre um número grande de discentes dentro de um espaço desafiador como é o laboratório. Neste sentido, a aula prática proposta não necessita necessariamente de um laboratório equipado, com vidrarias e equipamentos onerosos, mas sim, materiais simples e de baixo custo que podem ser facilmente adquiridos e utilizados na sala de aula ou até mesmo dentro de casa, uma vez que o ensino tem seguido o modelo virtual de ensino em detrimento à pandemia do novo coronavírus.

Desta forma, o principal objetivo deste trabalho é a proposta de uma aula prática utilizando materiais simples e de baixo custo, como o querosene, o álcool 70\%, água fervida, água gelada no processo de permeabilidade de membrana da beterraba (Beta vulgaris L.). Nesta aula os alunos poderão fortalecer o que foi aprendido nas aulas teóricas de Biologia Celular, facilitando assim o processo de aprendizagem. Pode ser também revisado diversos outros tópicos dentro da Biologia Celular como os aspectos estruturais da membrana plasmática, os processos de transporte além da interdisciplinaridade com a Botânica no que tange ao conceito de pigmentos vegetais (Betacianina da beterraba) e até mesmo ao estudo de morfologia da raiz.

Vale a pena ressaltarmos que, essa atividade possui duração média de realização de 40 minutos, e é fortemente recomendada aos alunos do primeiro ano do ensino médio, na temática de Citologia (estrutura e função da membrana plasmática).

\section{Metodologia}

A atividade proposta possui caráter qualitativo com uma abordagem didático-experimental possuindo base metodológica proposta por Pereira et al. (2018). O protocolo experimental foi em partes baseado no trabalho de Oliveira (2017). No entanto, no presente artigo, foram feitas modificações afim de tornar o experimento mais acessível aos alunos do ensino médio e inclusões, proporcionando uma maior discussão entre o professor e os alunos. 


\subsection{Materiais necessários para a condução da atividade}

Para a realização da aula prática proposta serão necessários os seguintes materiais:

- Metade de uma beterraba cortada em cubinhos pequenos (1,5 x 1,5 cm);

- Tubos de ensaio ou xícaras de café transparentes;

- Microondas ou fogão;

- Geladeira ou gelo;

- Água de torneira;

- Álcool 70\%;

- Querosene (adquirido em supermercados);

- Faca sem ponta;

- Papel toalha;

- Caneta de retroprojetor e uma seringa de $5 \mathrm{ml}$ (facilmente adquirida em farmácias).

\subsection{Preparo da beterraba e das xícaras/tubos}

A beterraba deverá ser cortada em pequenos cubos e retirada sua casca com auxílio de uma faca sem ponta. Nessa etapa, ressaltar aos alunos que peçam auxílio a um adulto, pois materiais cortantes como a faca podem ser perigosos. Após cortar as beterrabas, retirar o excesso do pigmento avermelhado (Betacianina) com o auxílio do papel toalha. Para isso, deve-se envolvê-las levemente para retirar o excesso desse pigmento. Para o tratamento 2, ferver um pouco de água, nessa etapa pedir o auxílio para um adulto. Para o outro tratamento (número 3), deixar um cubo de beterraba congelada (colocar alguns minutos no freezer da geladeira ou no gelo), retirar quando for fazer o experimento. Enumerar as xícaras com o auxílio do marcador de retroprojetor conforme as numerações que constam no Quadro 1.

\subsection{Realizando a atividade experimental}

Em cada uma das xícaras/tubos, os alunos deverão colocar um cubinho de beterraba e e preenchê-los por meio do uso de uma seringa, conforme constam as informações dos tratamentos constantes no Quadro 1. Deixar os tubos nos seus respectivos tratamentos em descanso por cerca 30 minutos, após isso, pedir aos alunos que anotem o que aconteceu em cada um deles, comparando o antes e o depois, formulando suas hipóteses. Para melhor comparação dos resultados, o professor pode sugerir aos alunos que tirem fotos das xícaras ou dos tubos, assim que terminarem de colocar o álcool no ultimo tratamento com a beterraba, e outra foto após 30 minutos de espera.

Quadro 1. Legendas das xícaras/tubos e tratamentos.

\begin{tabular}{|c|c|}
\hline NUMERAÇÕES DAS XÍCARAS/TUBOS & TRATAMENTOS \\
\hline 1 & Água da torneira $(4 \mathrm{ml})+1$ cubinho de beterraba in natura \\
\hline 2 & Água quente, fervida $(4 \mathrm{ml})+1$ cubinho de beterraba in natura \\
\hline 3 & Água da torneira $(4 \mathrm{ml})+1$ cubinho de beterraba congelada \\
\hline 4 & Querosene $(4 \mathrm{ml})+1$ cubinho de beterraba in natura \\
\hline 5 & Álcool $70 \%(4 \mathrm{ml})+1$ cubinho de beterraba in natura \\
\hline
\end{tabular}

Fonte: Autores. 


\section{Resultados e Discussão com Abordagens da Atividade no Escopo da Biologia}

Como resultado da presente atividade, o que podemos notar nos tubos de ensaio submetidos aos diferentes tratamentos? Na Figura 1, temos evidenciada as transformações ocorridas em cada um deles.

Figura 1. Cubos de beterraba (Beta vulgaris L.) em diferentes tratamentos, testando a influência na permeabilidade de suas membranas plasmáticas.

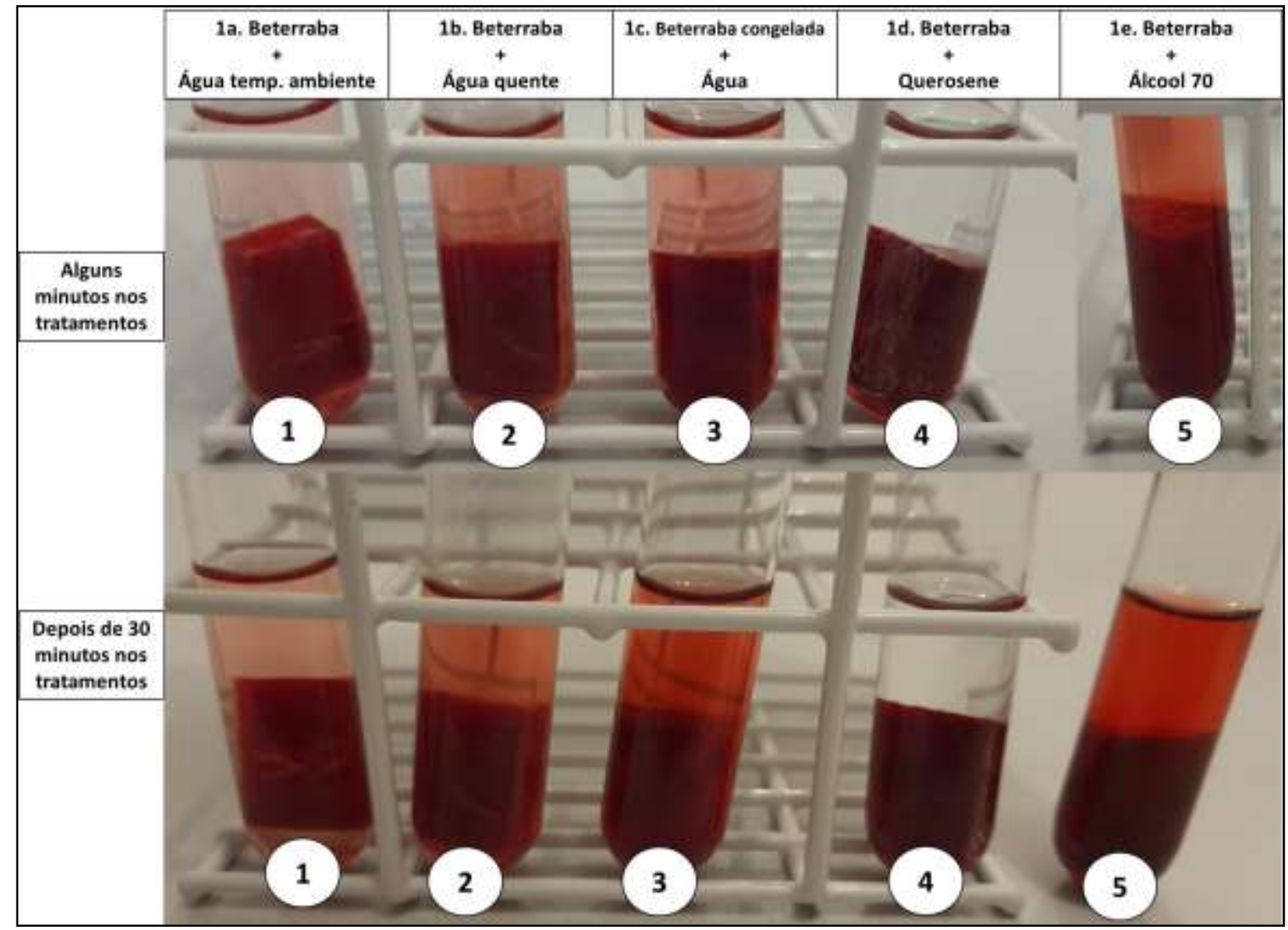

Fonte: Autores.

Inicialmente, é de grande importância o professor explicar sobre o pigmento que confere a cor vermelho arroxeada na beterraba. Na literatura, Gonçalves (2018), destaca que esse pigmento é derivado das Betalaínas possuindo uma coloração avermelhado/violeta, sendo caracterizado como uma Betacianina. Assim como afirma a autora, esses pigmentos podem ser encontrados em vários tecidos vegetais (folhas, caule, frutas, flores, raízes e sementes), e no caso da beterraba ela se encontra em suas raízes conferindo a cor vermelha arroxeada. Na célula, esse pigmento é encontrado dentro dos vacúolos, e são derivados do aminoácido tirosina, sendo solúveis em água (Tanaka, Sasaki \& Ohmiya, 2008; Gonçalves, 2018). Assim, no tubo de ensaio número 1 que é o nosso controle da reação, quando submetemos a beterraba em uma solução contendo água, os pigmentos de Betacianina irão extravasar de maneira pouco expressiva, do meio intracelular através de sua membrana plasmática indo para o meio extracelular, colorindo a água em um tom levemente avermelhado como podemos observar na Figura 1a. Dessa maneira deve ser ressaltado aos alunos que, o mecanismo de transporte celular que ocorre quando submetemos o cubo de beterraba na água é o transporte passivo do tipo "difusão". Nele, por meio da membrana teremos a saída do pigmento de Betacianina da beterraba em direção ao meio externo (água), a favor de um gradiente de energia livre, ou de potencial químico, até que o equilíbrio seja atingido (Taiz et al., 2017).

No tubinho número 2, o cubinho de beterraba foi submetido em um meio contendo $4 \mathrm{ml}$ de água quente (fervida). 
Nessa situação, o calor irá perturbar as estruturas da bicamada fosfolipídica, havendo um maior extravasamento de Betacianina para o meio externo quando comparado ao tubinho de número 1. (Figura 1b). Dessa maneira, a temperatura é um dos fatores que afetam a fluidez das membranas, fazendo com que os lipídios e as proteínas estejam menos compactados (Taiz et al., 2017), tornando a membrana mais permeável, mais fluída.

Já no tubinho número 3 (Figura 1c), a beterraba foi congelada. Nessa situação, ao congelarmos a beterraba, teremos a quebra (ruptura) dos seus tecidos celulares, assim quando colocada em meio aquoso, ocorrerá um extravasamento de Betacianina para o meio extracelular, podendo ser evidenciado uma coloração avermelhada intensa da água neste tubo (Fig. $3 c)$.

No tubinho de ensaio número 4 (Figura 1d), a beterraba foi submetida a uma solução de querosene. O querosene é um solvente altamente apolar, não ocorrendo afinidade com a membrana nem com o pigmento de Betacianina (polar). Assim, no tubinho de ensaio, o querosene permanecerá translúcido, ou seja, sem o extravasamento de Betacianina pela sua membrana.

Por fim, no tubo de ensaio 5 (Figura 1e), a beterraba foi colocada num meio contendo álcool 70\%. O álcool é uma molécula anfipática (ele é apolar e polar), havendo uma forte interação com a membrana celular e com a Betacianina, relaxando sua estrutura permitindo assim o extravasamento de Betacianina para o meio extracelular. Assim o álcool ficará bastante corado. (Figura 1e). Após discutir sobre o último tratamento na permeabilidade da membrana da beterraba, o professor pode chamar a atenção dos alunos que fatores como a temperatura (calor e o congelamento), a ação de solventes (querosene e o álcool) podem afetar a fluidez da membrana, que é o que foi observado em cada um dos tubos de ensaio

A próxima discussão que o professor poderá abordar é a respeito da importância da membrana plasmática nas células vegetais. Nas células vegetais como em todos os seres vivos, a membrana plasmática desempenha os papéis de controlar o transporte de substâncias tanto do meio intracelular para o meio extracelular (e vice-versa), além de garantir a integridade da célula, podendo até mesmo participar de mecanismos de reconhecimento célula a célula. Na literatura, Taiz et al. (2017, p. 143) ressaltam que a membrana plasmática celular vegetal também detecta informações sobre o ambiente, sobre sinais moleculares vindos de outras células e sobre a presença de patógenos invasores.

Outra questão interessante que o professor pode resgatar com essa aula experimental é sobre a parte da Botânica, no que tange a estrutura da raiz da planta da beterraba. A beterraba é uma planta originária da Europa, pertencente à família Quenopodiácea (Lana et al., 2016), e possui uma raiz do tipo tuberosa (Figura 2a). Nessa planta, os nutrientes se acumulam dentro da raiz, na região que fica embaixo da terra, e o caule fica acima da superfície (figura 2a) (Nunes, 2018). Como exemplo de outras plantas tuberosas temos a cenoura e a mandioca (Nabors, 2012).

Já a batata, (Figura 2b) é um exemplo de tubérculo, assim, os nutrientes se acumulam no seu caule e não na raiz como ocorre nas tuberosas. O caule é subterrâneo e possui um formato geralmente arredondado, com gemas, com formatos que lembram olhos, em reentrâncias, que são capazes de armazenar energia em forma de amido e inulina, entre outras substâncias (Nunes, 2018). No caso da cebola (Figura 2c), que é um bulbo, ela também possui um caule subterrâneo, mas seu formato é bem diferenciado, apresentando uma forma de um prato achatado. Assim, no seu caule, diferentemente da raiz é o local onde ocorre o armazenamento de nutrientes. (Nunes, 2018).

Outro assunto que o professor pode chamar a atenção dos alunos é o aspecto nutricional da beterraba na nossa dieta cotidiana. A beterraba é uma rica fonte de fibras e sacarose, um importante dissacarídeo composto por uma unidade de glicose e outra de frutose (Wikipedia, 2021). Segundo Ferreira e Tivelli (1990), sua raiz possui vitaminas do complexo B e os nutrientes como o potássio, sódio, ferro, cobre e zinco. Além da sua raiz, amplamente consumida, suas folhas também podem ser cozidas ou ingeridas cruas, sendo uma excelente fonte de proteínas (31, 54\%), fibras (10,18\%) e lipídios $(5,31 \%)$ (MATOS et al. 2009). 
Figura 2. Diferenças entre as Raízes: a) Raiz tuberosa, b) Tubérculo e c) Bulbo.

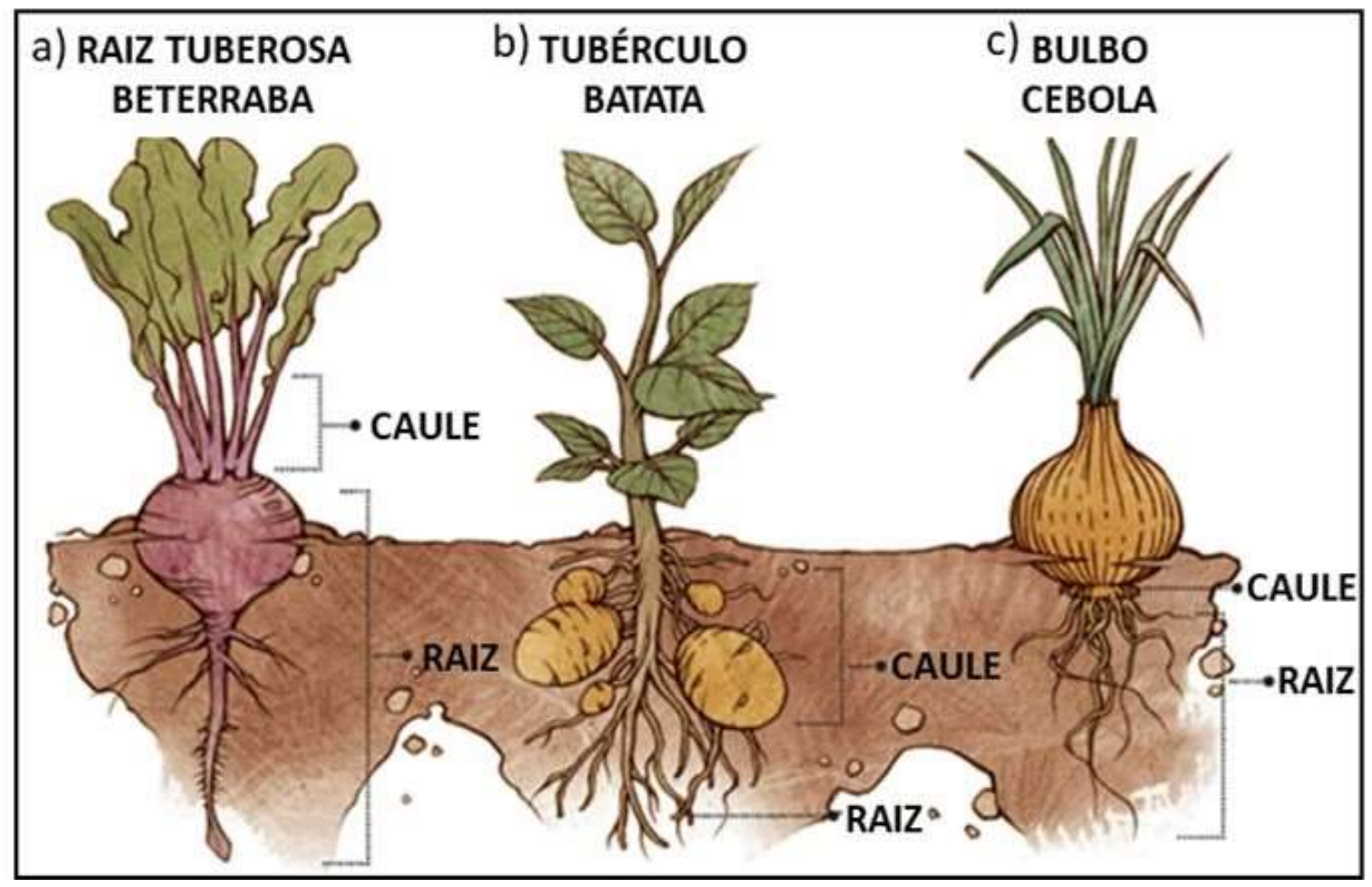

Fonte: Fonte: Ilustração de Sandro Castelli com modificações. https://novaescola.org.br/conteudo/169/qual-diferenca-entreraiz-tuberosa-tuberculo-bulbo-caule-cebola-batata-beterraba

Para potencializar a aprendizagem, no próximo tópico deste artigo, é proposto um banco de questões que poderão ser respondidos pelos alunos no fim da atividade prática e entregue ao professor para correção. Como as aulas estão seguindo o modelo virtual de ensino, essa atividade prática pode ser demonstrada virtualmente pelo professor aos alunos, que em suas casas poderão replicar o experimento, utilizando materiais simples e de baixo custo.

Vale a pena ressaltarmos que, além das questões que poderão ser respondidas pelos alunos, pode ser sugerido pelo professor a confecção de um relatório, com os resultados da aula prática proposta, reforçando ainda mais o que foi aprendido. No tópico 5, encontram-se as respostas esperadas das questões. Assim, em um próximo encontro, o professor pode discutir as respostas e sanar as possíveis dúvidas com os alunos.

\section{Questões Propostas}

1) O que aconteceu em cada um dos tubos/xícaras? Formule uma hipótese para explicar os fenômenos ocorridos.

2) Porquê dizemos que a membrana plasmática é SELETIVA? Justifique sua resposta.

3) Se ao invés de adicionarmos álcool 70\% no tubo de número 5, nós adicionarmos um pouco de gasolina, o que você esperaria que ocorresse? Justifique sua resposta e faça um desenho para explicá-la.

4) A membrana plasmática constitui uma importante estrutura celular. Descreva suas principais funções.

5) Quais são os principais fatores que podem afetar a permeabilidade das membranas? Escolha um deles, e explique-o de maneira mais detalhada. 


\section{Respostas Esperadas das Questões}

1) Tubo 1: controle: ocorreu pouca saída de Betacianina, a água ficou pouco avermelhada.

Tubo 2: com a água fervente, a membrana plasmática da beterraba ficou mais permeável, ocorrendo desprendimento da Betacianina. Assim, o pigmento saiu das células da beterraba passando pela sua membrana e saindo para o meio externo (água). Observamos a coloração avermelhada da água.

Tubo 3: com ela congelada, sua membrana foi danificada, havendo abertura da membrana plasmática e saída de Betacianina do meio intracelular para o meio extracelular por meio da membrana plasmática. Assim, a água fica colorida.

Tubo 4: Como o querosene é apolar não ocorreu interação com a membrana vem com a Betacianina. Assim, esse pigmento permaneceu no meio interno da célula. O querosene ficou translúcido, ou seja, sem pigmentos de Betacianina da beterraba;

Tubo 5: Como o álcool tem caráter anfipático, ele permite a interação da membrana plasmática e da Betacianina da beterraba ocorrendo um desprendimento expressivo de desse pigmento para o meio externo. Como resultado, o álcool ficou bastante avermelhado.

Hipótese I: a membrana plasmática é permeável, transportando substâncias e seleciona o que passa e o que não passa do meio intra para o meio extracelular e vice-versa.

Hipótese II: a membrana plasmática pode sofrer a interação da temperatura (calor, congelamento) e de solventes (querosene e álcool) afetando sua estrutura e sua permeabilidade.

2) A membrana plasmática é dita seletiva pois ela seleciona o que passa e o que não passa do meio intra para o meio extracelular e vice-versa.

3). No tubo de número 5, ao invés do álcool for adicionado gasolina, teremos o mesmo fenômeno ocorrido no tubo de ensaio número 4. Ou seja, assim como o querosene, a gasolina é apolar, não se relacionando com a Betacianina nem com membrana plasmática. Dessa forma, a Betacianina da beterraba que está no meio interno da célula não irá se extravasar, permanecendo um líquido translúcido a amarelado que é a cor da gasolina. No desenho deverá ser representado o tubo (ou xícara) com o cubo de beterraba embebido na solução de gasolina. A beterraba deverá ser pintada de vermelho e a solução estará com coloração transparente ou amarela (cor da gasolina), não ocorrendo extravasamento de Betacianina (pigmento vermelho da beterraba).

4). A membrana plasmática possui como funções: transporte de substância, manutenção da integridade interna celular, reconhecimento célula a célula, proteção.

5) Os principais fatores que podem afetar a permeabilidade das membranas são: temperatura, solventes, pressão, $\mathrm{pH}$.

Explicando o fator temperatura: o fator temperatura altera o grau de fluidez da bicamada lipídica. Assim, ela pode ficar mais fluída (ocasionado por um aumento de temperatura, que leva a uma maior passagem de substâncias, pois a membrana estará mais permeável), ou mais rígida (diminuição de temperatura pela presença de cristais de gelo, o que pode ocasionar a ruptura das membranas ocasionando um aumento de permeabilidade).

\section{Considerações Finais}

Pelo experimento proposto, os alunos poderão observar que diversos fatores como a temperatura (calor e o 
congelamento), a ação de solventes (querosene e o álcool) afetam a fluidez da membrana, permitindo ou não a saída de substâncias que por ventura estão presentes no meio interno da célula (Betacianina da beterraba) para o meio extracelular, o que é evidenciado pelas colorações aquosas dos tubos de ensaio. Assim, essa aula prática se desponta como um valioso recurso metodológico qualitativo, facilitando a aprendizagem da temática proposta, resgatando na prática o que foi aprendido nas aulas teóricas, na disciplina de Biologia. Além disso, a prática proposta pode facilitar a aprendizagem de outros assuntos, como a estrutura tridimensional da membrana plasmática, mecanismos de transportes celular, além de suas funções que são desempenhadas na célula. Além do escopo da Citologia, essa atividade permite ao professor trabalhar com os alunos a área da Botânica e até mesmo aspectos nutricionais da beterraba em nossa dieta cotidiana.

Como sugestão de um trabalho futuro, será de grande relevância a construção e implementação de um modelo didático tridimensional da membrana plasmática celular, utilizando materiais simples e de baixo custo, como bolas de isopor, tintas coloridas, massa de biscuit e palitos de dente. Esse trabalho poderá vir a complementar a aprendizagem da temática proposta, uma vez que a Biologia Celular (Citologia) possui assuntos microscópicos e abstratos e a construção e abordagem de um modelo 3D da membrana plasmática irá auxiliar os alunos do ensino médio em uma melhor compreensão da sua estrutura morfológica.

\section{Referências}

Alffonso, C. M. (2019). Práticas inovadoras no ensino de ciências e biologia: diversidade na adversidade. Revista Formação e Prática Docente. 2, 69-85. http://www.revista.unifeso.edu.br/index.php/revistaformacaoepraticaunifeso/article/view/695/659

Ferreira, M. D., \& Tivelli, S.W (1990). Cultura da beterraba: recomendações gerais. Cooxupé.

Goldschimidt, A. I., Michel, D. C., Fontana, L. B., Rangel, C., Brizola da Silva, W., Novaes. L. A.; \& Tissot, C. (2020). Bicho de sete cabeças: uma proposta para o ensino da célula e da anatomia humana. REPPE: Revista do Programa de Pós-Graduação em Ensino. (4)2, 23-39. http://seer.uenp.edu.br/index.php/reppe/article/view/2000/914

Gonçalves, B. S. G. (2018). Pigmentos Naturais de Origem Vegetal: Betalaínas. Dissertação (Mestrado em Ciências Farmacêuticas), Faculdade de Ciências e Tecnologias, Universidade do Algarve. Faro, Portugal.

Gonçalves, T. M. (2021). A guerra imunológica das células contra os patógenos: a proposta de um modelo didático tridimensional de baixo custo para simulação da resposta imune celular mediada por linfócitos $\mathrm{T}$ CD8+. Brazilian Journal of Development, 7(1), 4.854-4.860. https://www.brazilianjournals.com/index.php/BRJD/article/view/23099/18554

Lana, M. M., Santos, F. F., Matos, M. J. L., Tavares, S. A., \& Melo, M. F. (2016). Hortaliça, como comprar, conservar e consumir: Beterraba. $2^{a}$ edição, EMBRAPA e EMATER - DF. https://www.embrapa.br/documents/1355126/31107372/BETERRABA_CCCC_2017.pdf/9d77503c-d3cf-2f58-b2c1bd1df3c9bf5a

Marandino, M., Selles, S. E., Ferreira, M. S. (2009). Ensino de Biologia: histórias e práticas em diferentes espaços educativos. Cortez Editora.

Matos, I. A. F., Macedo, D. C., Ciabotti, S. Pereira, L. A., \& Alvarenga, C. A. (2009, outubro). Avaliação da composição centesimal de folhas de beterraba comparadas com espinafre. II Seminário Iniciação Científica - IFTM, Campus Uberaba, MG, Brasil.

Nabors, M. W. Introdução à Botânica. (2012).

Nunes, R. (2018). Qual a diferença entre raiz tuberosa, tubérculo e bulbo? https://novaescola.org.br/conteudo/169/qual-diferenca-entre-raiz-tuberosatuberculo-bulbo-caule-cebola-batata-beterraba

OLIVEIRA, S. C. C. (2017). Permeabilidade de membrana - beterraba. https://www.youtube.com/watch?v=fDHBaUp3U_U

Pereira A. S., Shitsuka, D. M., Parreira, F. J., \& Shitsuka, R. (2018). Metodologia da pesquisa científica. UFSM. https://repositorio.ufsm.br/bitstream/han dle/1/15824/Lic_Computacao_Metodologia-Pesquisa-Cientifica.pdf?sequence $=1$.

Pimentel, P. M. S., Oliveira, M. V. P., \& Maciel, E. M. (2017). Teoria e prática no âmbito do ensino médio: análise de casos no Piauí e Ceará para o ensino de biologia. REnCIMA. (8)3, 158-173. http://revistapos.cruzeirodosul.edu.br/index.php/rencima/article/view/1200/902

Rocha, N. C., Vasconcelos, B., Maia, J. C., Gallão, M. I., Rodrigues, D. A. M., \& Hissa, D. C. (2017). Jogo didático “síntese proteica” para favorecer a aprendizagem de biologia celular. Experiências em Ensino de Ciências. 12(2), 129-137. https://if.ufmt.br/eenci/artigos/Artigo_ID353/v12_n2_a2017.pdf

Singer, S. J., \& Nicolson, G. L. (1972). The Fluid Mosaic Model of the Structure of Cell Membranes. Science. (175)4023, 720-731. https://science.sciencemag.org/content/175/4023/720/tab-article-info

Taiz, L., Zeiger, E., Moller, I. M., Murphy, A. (2017) Fisiologia e Desenvolvimento Vegetal. (6a ed.), ARTMED. 
Research, Society and Development, v. 10, n. 3, e30010313479, 2021

(CC BY 4.0) | ISSN 2525-3409 | DOI: http://dx.doi.org/10.33448/rsd-v10i3.13479

Tanaka, Y., Sasaki, N., \& Ohmiya, A. (2008). Biosynthesis of plant pigments: Anthocyanins, Betalains and Carotenoids. The Plant Journal, 54, 733-749. 